\title{
Continuidad en la publicación de la Revista Científica
}

La publicación de los artículos científicos, derivados de las investigaciones, constituye la misión primordial de las Revistas Científicas, lo que representa su contribución al crecimiento y desarrollo del acervo del conocimiento, lo que en primer lugar nos permite lograr un mejor entendimiento, en nuestro caso, de las actividades humanas relacionadas con las Ciencias Veterinarias, y su consecuente contribución al bienestar de la Sociedad, amén de los múltiples beneficios derivados de dicha actividad.

Al publicar el resultado de nuestras investigaciones estamos cumpliendo un compromiso con las generaciones futuras, un aporte necesario para que el desarrollo de la sociedad tienda a ser lo más armónico posible, pues para ello son necesarios los aportes que en cada área del conocimiento se producen día a día. Tanto por lo que constituye el conocimiento legado, como por el estímulo intrínseco a la dinámica del proceso articulado de investigación - conocimiento, conformando así un apoyo fundamental de la SOCIEDAD DEL CONOCIMIENTO.

En la actualidad, la investigación en Venezuela atraviesa por uno de sus momentos más oscuros; pues al no contar con los recursos que anteriormente contábamos con mayor disponibilidad, eventualmente el ánimo pueda haber decaído un poco y el impulso que se le venía imprimiendo a las investigaciones posiblemente haya sufrido cambios; lo cierto es que esas transformaciones son el resultado del proceso continuo de adaptación al nuevo escenario, proceso que ha tenido que ser acelerado pues se han conjugado además de factores económicos, la situación de pandemia del COVID-19, de manera que la capacidad de adaptación y resiliencia se ha visto sometida a una prueba más extrema que la que día a día venía enfrentando el investigador. Lo que en consecuencia está generando investigadores con un umbral de resistencia a la adversidad también mayor.

No obstante, esta no es una situación exclusiva del País, ni la primera de este estilo que enfrenta el investigador nacional, ni mucho menos la última. Afortunadamente, tampoco es característico en los investigadores quedarse reflexionando con una visión negativa sobre las condiciones que se constituyen en una estructura de freno, al contrario, la determinación del investigador está conformada en principio para enfrentar y superar retos, así que las condiciones adversas de una situación circunstancial no son las que van a evitar el avance de la investigación, posiblemente durante el proceso resulten algunos fracasos parciales, que serán superados por nuevos intentos, nuevos actores y escenarios que irán posibilitando el progreso necesario.

El mayor estímulo es que hay mucho por investigar, las adversidades no van a dejar de existir; pero el balance siempre va a resultar en favor de la Investigación y la Revista Científica FCV-LUZ no dejara de insistir en el logro de esos objetivos.

Nidia Rojas

Directora de la División de Investigación de la FCV

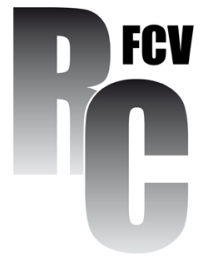

